\title{
IMPACT OF STRESS RESPONSE IN DEVELOPMENT OF FIRST-EPISODE PSYCHOSIS IN SCHIZOPHRENIA: AN OVERVIEW OF SYSTEMATIC REVIEWS
}

\author{
Linda Rossini Gajsak ${ }^{1}$, Andrea Gelemanovic ${ }^{2}$, Martina Rojnic Kuzman ${ }^{3}$ \& Livia Puljak ${ }^{4}$ \\ ${ }^{1}$ Neuropsychiatric Hospital Dr. Ivan Barbot, Popovaca, Croatia \\ ${ }^{2}$ University of Split, School of Medicine, Split, Croatia \\ ${ }^{3}$ Zagreb School of Medicine and University Hospital Center Zagreb, Zagreb, Croatia \\ ${ }^{4}$ Laboratory for Pain Research, Cochrane Croatia, University of Split, School of Medicine, Split, Croatia
}

received: 10.01.2017; $\quad$ revised: 15.02.2017; $\quad$ accepted: 22.02.2017

\begin{abstract}
SUMMARY
Background: To summarize all available evidence from systematic reviews about the impact of stress response in development of first-episode psychosis (FEP) in schizophrenia.

Methods: An overview of systematic reviews of any type of primary studies was performed. An electronic search of five databases was conducted in February 2017 (CDSR, DARE, Embase, MEDLINE and PsychINFO). Quality of included systematic reviews was assessed using the AMSTAR checklist.

Results: Eight systematic reviews were included. The main findings of the included reviews point out a possible alteration of the stress response in a subgroup of persons with proneness to psychosis. However, the evidence is limited by the inadequate quality of studies, as well as lack of standardization of outcomes and assessment methods.

Conclusions: Given the heterogeneity of current results, there is no solid evidence for uniform alterations of stress response found in persons with FEP in suggestive of schizophrenia that may serve as a marker of vulnerability to stress and possibly proneness to psychotic state in response to daily hassles.
\end{abstract}

Key words: cortisol - hydrocortisone - stress - first-episode psychosis - schizophrenia

\section{INTRODUCTION}

Schizophrenia is a chronic, recurrent disease that usually starts with a first psychotic episode and continues with periods of remission and acute psychosis.

While treatment response is achieved for up to $90 \%$ of persons with the first-episode psychosis (FEP) by the end of the first years of treatment, due to treatment nonadherence, the majority of patients relapse within a few years (Emsley 2013). Thus, over its course, schizophrenia still remains a disorder with low functional recovery rates (Jaaskelainen et al. 2013, Wunderink et al. 2013) and it is associated with poor quality of life in patients and their families (Wittchen et al. 2011).

While the pathogenesis of schizophrenia is still largely unknown, a large body of genetic studies concluded that schizophrenia results from the gene $\mathrm{x}$ environment interaction (or epigenetic effects on the genome) (van Os \& Kapur 2009). This once again revitalized the stress diathesis model of schizophrenia. This model implies that interaction of genes and environmental influences, including a variety of biological/chemical factors (infections, diseases), psychological stressors (mother-infant relationship, family dynamics, life events, childhood trauma) and social factors (society, migration) shape the vulnerability to schizophrenia (Bale et al. 2010, Beards et al. 2013, Holtzman et al. 2013, Van Winkel et al. 2010, Zannas \& West 2014).
Stress response implies the activation of the hypothalamus-pituitary-adrenal (HPA) axis, which is activated by the release of corticotropin-releasing hormone (CRH) and of vasopressin (AVP), synthesized in the hypothalamus, which activate the secretion of adrenocorticotropic hormone (ACTH) from the pituitary, which finally stimulates secretion of cortisol from the adrenal gland. Cortisol subsequently initiates cascade effects in a number of systems (immune, neuroendocrine, inflammatory response, etc.), Alterations of stress response are thus reflected in the alterations of the HPA axis, and can be measured by the cortisol response, including cortisol and ACTH levels, non-suppression of cortisol secretion by dexamethasone in the dexamethasone suppression test, and in the dexamethasone/CRH test (Walker 2016).

A significant number of findings in patients with first psychotic episode of schizophrenia could be related to alterations of stress response. These include altered HPA axis functions (Borges et al. 2013, Cullen et al. 2014), increased baseline prolactin (Kahn et al. 2008), alterations in immune system (Miller et al. 2011), genetic expression of inflammatory markers (Gardiner et al. 2013) or neurocognitive dysfunctions (O'Connor et al. 2013) etc. Some of the stress biomarkers may be present even among persons at risk for psychosis (Mizrahi et al. 2012, Pruessner et al. 2013). 
Table 1. Example of search strategy on impact of stress in development of psychotic disorders designed for Ovid MEDLINE and conducted on February 9, 2016

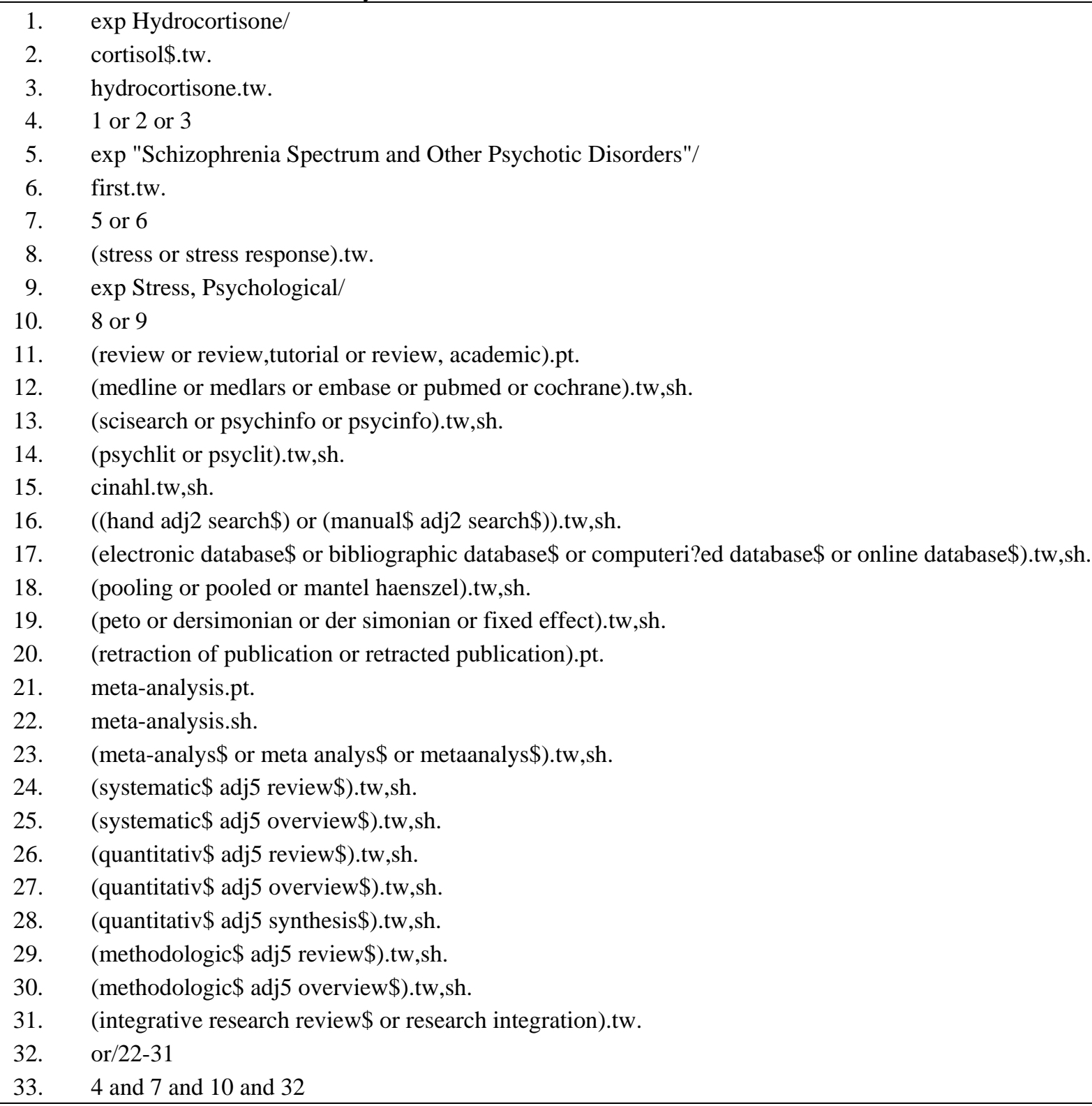

Several systematic reviews attempted recently to summarize the current knowledge about the stress response impact in the development of first psychotic episode. The main findings of the reviews point out a possible alteration of the stress response, reflected by alterations of cortisole and ACTH blood levels in response to stress or pituitary volume (Aiello et al. 2012, Borges et al. 2013). However, in the majority of reviews, conflicting findings were reported as well (Borges et al. 2013, Ciufolini et al. 2014, Girshkin et al. 2014).

The aim of this study was to conduct an overview of all those systematic reviews in order to ascertain the role of the vulnerability to stress in the development of first psychotic episode, to provide recommendations for practice and to identify knowledge gaps that will guide further research.

\section{METHODS}

\section{Study protocol}

A protocol for this overview of systematic reviews was developed a priori and registered in the PROSPERO International Prospective Register of Systematic Reviews (No. CRD42016042155).

\section{Literature search}

The search was performed to find relevant studies from the five databases, including Cochrane Database of Systematic Reviews (CDSR), Database of Reviews of Effects (DARE), Embase, MEDLINE and PsychINFO. Each database was searched from its inception to February 9, 2017. A complex search strategy was crea- 
ted encompassing search terms related to hydrocortisone, cortisol, stress and stress response, combined with key words for schizophrenia spectrum and other psychotic disorders. Search strategy was created for MEDLINE first (Table 1) and then adapted for other databases. The search was restricted to peer-reviewed journals and English language. Search strategy was very wide on purpose, in order to include all systematic reviews on association between stress, levels of cortisol and psychotic disorders.

\section{Eligibility criteria}

\section{Types of studies}

We included systematic reviews of any type of primary studies. Systematic reviews that were done by one author only or were using only one database for article search, were discarded as they do not meet the requirements of systematic review.

\section{Participants and outcomes}

We included systematic reviews that assessed impact of stress in the development of FEP in schizophrenia spectrum disorders according to the criteria of ICD-10 or DSM-IV or DSM-5.

\section{Study selection}

One author (LP) conducted the searches; two authors independently (LRG and AG) screened all retrieved bibliographic records against the inclusion criteria.
Potentially eligible systematic reviews were analyzed in full text by two authors (LRG and AG) independently. A third (LP) and the fourth author (MRK) were consulted in cases of disagreement.

\section{Data extraction and management}

A data collection form was developed and tested prior to starting the review. Two authors (LRG and AG) extracted the data independently and compared results afterwards. Disagreements were resolved by a third author (LP). Data extracted included review details (author, title and publication year), review aims, inclusion/exclusion criteria, date of last search and main findings about the impact of stress in development of the first psychotic episode. Authors of the included reviews were not contacted for further information. Data were presented narratively and in tabular form. For systematic reviews that included patients with more than one disease, only data regarding schizophrenia patients were reported. Articles with one author and only one database searched were excluded due to lack of systematic reviewing norms.

\section{Quality assessment of included systematic reviews}

Two authors (LRG and AG) independently assessed the methodological quality of the included systematic reviews using the AMSTAR checklist (Shea 2007). Disagreements regarding AMSTAR score were resolved by discussion or a decision made by a third author (LP).

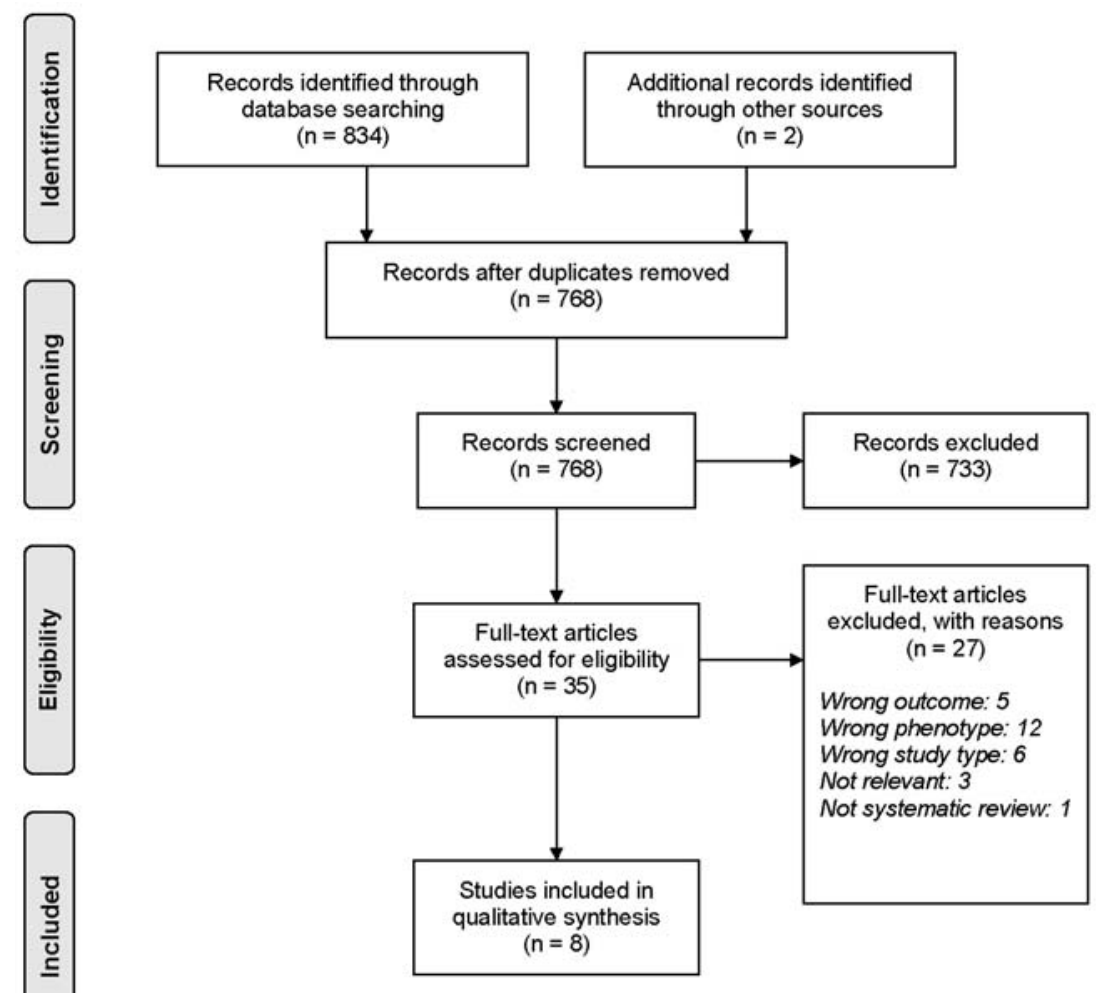

Figure 1. Search strategy flowchart, according to PRISMA guidelines 


\section{RESULTS}

\section{Literature search}

Initial database searching yielded 834 bibliographic records. After deletion of duplicates and screening of titles and abstracts, 35 full texts were analyzed, of which eight met all the inclusion criteria (Aiello et al. 2012, Berger et al. 2016, Borges et al. 2013, Chaumette et al. 2015, Ciufolini et al. 2014, Fond et al. 2015, Girshkin et al. 2014, Lange et al. 2016) and 27 were excluded with reasons (Table 2). The study selection process is presented in Figure 1.

\section{Characteristics of included systematic reviews}

All included systematic reviews were published recently, between 2012 and 2016, and the main characteristics of each included systematic reviews are summarized in Table 3. Inclusion criteria were slightly different among the selected systematic reviews: some explicitly indicated that included patients suffered from first-episode psychosis (Borges et al. 2013, Chaumette et al. 2015, Ciufolini et al. 2014, Fond et al. 2015); others only stated schizophrenia, but considering the use of different classification we considered them also to be relevant (Aiello et al. 2012, Borges et al. 2013, Ciufolini et al. 2014, Girshkin et al. 2014). Even though our primary idea was to identify adult-based studies, one systematic review also included studies with patients above 15 years of age (Chaumette et al. 2015). Only two systematic reviews did not specify their exclusion criteria (Aiello et al. 2012, Fond et al. 2015), while others had similar exclusion criteria, including studies with already published samples, physical illness, naturalistic stressors, metabolically demanding tasks, studies with imaging tasks, or with reactivity to stress, urinary cortisol measures, comments, abstracts and reviews. Half of the included systematic reviews had also performed a meta-analysis (Berger et al. 2016, Chaumette et al. 2015, Ciufolini et al. 2014, Girshkin et al. 2014). Other main characteristics of each included systematic review are shown in Table 3.

\section{Main findings of included systematic reviews}

Aiello et al. analyzed stress abnormalities in individuals at risk of psychosis. They reported that relatives of patients with schizophrenia had increased ACTH blood levels in response to stress and increased pituitary volume, whereas from three studies on cortisol level after stress exposure in relatives only one found increased cortisol levels. Studies on pituitary volume showed that HPA axis hyperactivity is already present before the onset of psychosis in patients with ultra-high risk for psychosis (UHR-P) compared to controls (ultrahigh risk who did not convert to psychosis, UHR-NP). Studies on hippocampus showed that some authors noticed a hippocampal volume increase in participants who made the transition to psychosis, despite the increased activity in the same participants. This review concluded that enhanced response of HPA axis to stress may be part of biological vulnerability to psychosis, which is present already before the psychosis onset (Aiello et al. 2012).

Berger et al. investigated cortisol awakening response (CAR) among the patients along the psychosis continuum including schizophrenia, first-episode psychosis, and atrisk metal states (ARMS) compared to healthy controls. Flattened CAR was found in patients with schizophrenia and first-time psychosis, but not in those at-risk. The authors conclude that CAR may be important marker for transition risk, but warn about methodological problems in included studies, such as small number of studies, small sample sizes and different scales being used for scoring symptom severity (Berger et al. 2016).

Borges et al. reported that 6 primary studies on cortisol levels found higher plasma cortisol levels when comparing patients with FEP with healthy controls, while 4 studies showed no significant difference. Studies on pituitary volume showed that 4 studies reported a larger pituitary volume comparing FEP with healthy controls, while 5 studies showed no significant difference. Additionally, 2 studies showed that longer duration of psychosis was associated with a reduction in pituitary volume, while 3 studies showed that prolactinenhanced antipsychotics were associated with larger pituitary volume. They concluded that patients with FEP exhibit specific pattern of HPA axis hyperactivity, as evidenced by higher baseline cortisol levels compared to controls, blunted cortisol awakening response and enlarged pituitary on MRI scan (Borges et al. 2013).

Chaumette et al. showed no significant difference in cortisol levels in the first French cohort of young helpseekers (ICAAR, Influence du Cannabis sur l'émergence de symptômes psychopathologiques des Adolescents et jeunes Adultes présentant un état mental à Risque) or when comparing FEP with control group. Studies on cortisol levels in UHR showed slightly higher salivary cortisol level at baseline than healthy controls. Their meta-analysis revealed a significantly higher salivary basal cortisol levels in UHR compared to controls, but none between FEP and controls or UHR and FEP. They warn that their results indicate that basal levels of cortisol may not be used as a reliable biomarker of early psychosis (Chaumette et al. 2015).

Ciufolini et al. included three studies with individuals with schizophrenia and used meta-analysis to investigate HPA axis response to social stress. The results showed that subjects with schizophrenia have lower cortisol levels in preparation and during the tasks of the stress response tests (Ciufolini et al. 2014).

Fond et al. showed that multiple studies reported a basal hyperactivity of the HPA axis in male patients with FEP and that it may be correlated with disease severity. Also, it was found that antipsychotics can normalize diurnal cortisol hypersecretion, but they did not blunt cortisol awakening response in FEP (Fond et al. 2015). 
Table 2. List of excluded studies after full text screening, with reasons

\begin{tabular}{|c|c|c|}
\hline Author & Title & Reason for exclusion* \\
\hline $\begin{array}{l}\text { Aguero-Tejado } \\
2014\end{array}$ & $\begin{array}{l}\text { Short polymorphism of the serotonin transporter (5-HTTLPR) gene and its } \\
\text { association with the cortisol stress response: A meta-analysis }\end{array}$ & Wrong outcome \\
\hline $\begin{array}{l}\text { Alexander et al. } \\
2014\end{array}$ & $\begin{array}{l}\text { DNA methylation profiles within the serotonin transporter gene moderate } \\
\text { the association of 5-HTTLPR and cortisol stress reactivity }\end{array}$ & Wrong outcome \\
\hline $\begin{array}{l}\text { Baumeister et al. } \\
2014\end{array}$ & $\begin{array}{l}\text { The interface of stress and the HPA axis in behavioural phenotypes } \\
\text { of mental illness }\end{array}$ & Wrong study type \\
\hline $\begin{array}{l}\text { Belvederi Murri } \\
\text { et al. } 2016\end{array}$ & The HPA axis in bipolar disorder: Systematic review and meta-analysis & Wrong phenotype \\
\hline Birkett 2011 & The Trier Social Stress Test protocol for inducing psychological stress & Not relevant \\
\hline $\begin{array}{l}\text { Bradley \& Dinan } \\
2010\end{array}$ & $\begin{array}{l}\text { A systematic review of hypothalamic-pituitary-adrenal axis function in } \\
\text { schizophrenia: implications for mortality }\end{array}$ & Wrong study type \\
\hline $\begin{array}{l}\text { Chaumette et al. } \\
2016\end{array}$ & $\begin{array}{l}\text { Stress and psychotic transition: } \\
\text { A literature review }\end{array}$ & $\begin{array}{l}\text { Tarrative review (not systematic } \\
\text { review); not in English }\end{array}$ \\
\hline $\begin{array}{l}\text { Chida \& Steptoe } \\
2009\end{array}$ & $\begin{array}{l}\text { Cortisol awakening response and psychosocial factors: } \\
\text { A systematic review and meta-analysis }\end{array}$ & Wrong phenotype \\
\hline $\begin{array}{l}\text { Dickerson \& } \\
\text { Kemeny } 2004\end{array}$ & $\begin{array}{l}\text { Acute stressors and cortisol responses: } \\
\text { A theoretical integration and synthesis of laboratory research }\end{array}$ & Wrong phenotype \\
\hline Egliston et al. 2007 & $\begin{array}{l}\text { Stress in pregnancy and infant HPA axis function: Conceptual and methodo- } \\
\text { logical issues relating to the use of salivary cortisol as an outcome measure }\end{array}$ & Wrong phenotype \\
\hline Hellhammer 2011 & The Trier Social Stress Test (TSST) - A valid tool for clinical studies & Not relevant \\
\hline $\begin{array}{l}\text { Hjortskov et al. } \\
2004\end{array}$ & $\begin{array}{c}\text { Evaluation of salivary cortisol as a biomarker of self-reported } \\
\text { mental stress in field studies }\end{array}$ & Wrong phenotype \\
\hline Jansen et al. 2010 & Cortisol reactivity in young infants & Wrong phenotype \\
\hline $\begin{array}{l}\text { Jessop \& Turner- } \\
\text { Cobb } 2008\end{array}$ & $\begin{array}{l}\text { Measurement and meaning of salivary cortisol: A focus on health and } \\
\text { disease in children }\end{array}$ & Wrong phenotype \\
\hline $\begin{array}{l}\text { Karanikas \& } \\
\text { Garyfallos } 2015\end{array}$ & $\begin{array}{l}\text { Role of cortisol in patients at risk for psychosis mental state and } \\
\text { psychopathological correlates: A systematic review }\end{array}$ & Wrong study type \\
\hline $\begin{array}{l}\text { Karanikas et al. } \\
2014\end{array}$ & The role of cortisol in first episode of psychosis: a systematic review & Wrong study type \\
\hline $\begin{array}{l}\text { Kirschbaum \& } \\
\text { Hellhammer } 1994\end{array}$ & $\begin{array}{l}\text { Salivary cortisol in psychoneuroendocrine research: } \\
\text { Recent developments and applications }\end{array}$ & Wrong study type \\
\hline Miller et al. 2007 & $\begin{array}{l}\text { If it goes up, must it come down? } \\
\text { Chronic stress and the hypothalamic-pituitary-adrenocortical axis in humans }\end{array}$ & Wrong phenotype \\
\hline Miller et al. 2013) & $\begin{array}{c}\text { The serotonin transporter gene-linked polymorphic region (5-HTTLPR) and } \\
\text { cortisol stress reactivity: A meta-analysis }\end{array}$ & Wrong outcome \\
\hline $\begin{array}{l}\text { Nordholm et al. } \\
2013\end{array}$ & $\begin{array}{l}\text { Pituitary gland volume in patients with schizophrenia, subjects at ultra high risk } \\
\text { of developing psychosis and healthy controls: A systematic review and meta-analysis }\end{array}$ & Wrong outcome \\
\hline Stalder et al. 2017 & $\begin{array}{l}\text { Stress-related and basic determinants of hair cortisol in humans: } \\
\text { A meta-analysis }\end{array}$ & Wrong phenotype \\
\hline $\begin{array}{l}\text { Staufenbiel et al. } \\
2013\end{array}$ & $\begin{array}{c}\text { Hair cortisol, stress exposure, and mental health in humans: } \\
\text { A systematic review }\end{array}$ & Wrong phenotype \\
\hline $\begin{array}{l}\text { Tanaka \& Naruishi } \\
2008\end{array}$ & $\begin{array}{l}\text { Development of an on-site measurement system for salivary stress-related } \\
\text { substances based on microchip capillary electrophoresis technology }\end{array}$ & Not relevant \\
\hline $\begin{array}{l}\text { Van Andel et al. } \\
2014\end{array}$ & $\begin{array}{c}\text { Salivary cortisol: A possible biomarker in evaluating stress and effects } \\
\text { of interventions in young foster children? }\end{array}$ & Wrong phenotype \\
\hline $\begin{array}{l}\text { Van Winkel et al. } \\
2013\end{array}$ & $\begin{array}{l}\text { Childhood trauma as a cause of psychosis: } \\
\text { Linking genes, psychology, and biology }\end{array}$ & Wrong outcome \\
\hline Volko et al. 2016 & $\begin{array}{l}\text { Model approach for stress induced steroidal hormone cascade changes } \\
\text { in severe mental diseases }\end{array}$ & Wrong phenotype \\
\hline Zorn et al. 2017 & $\begin{array}{c}\text { Cortisol stress reactivity across psychiatric disorders: } \\
\text { A systematic review and meta-analysis }\end{array}$ & Wrong study type \\
\hline
\end{tabular}

\section{* Definition of exclusion criteria:}

Wrong outcome: effect of gene polymorphism on cortisol and stress response/volume of pituitary volume gland and onset of psychosis/childhood trauma and psychosis;

Wrong phenotype: cortisol response in bipolar disorder/first psychotic episode not specified/healthy individuals/children/ infants/prenatally stressed women/self-reported mental stress at the work place;

Wrong study type: not systematic review (articles with one author; only one database searched);

Not relevant: TSST protocol/measurement system for salivary stress-related substances. 
Table 3. Study characteristics of included systematic reviews

\begin{tabular}{|c|c|c|c|c|c|c|}
\hline Study, year & $\begin{array}{l}\text { Search } \\
\text { date }\end{array}$ & Databases & $\begin{array}{c}\mathrm{N} \text { of } \\
\text { studies }\end{array}$ & $\begin{array}{c}\mathrm{N} \text { of } \\
\text { participants }\end{array}$ & $\begin{array}{c}\text { Age of } \\
\text { participants }\end{array}$ & Outcome \\
\hline $\begin{array}{l}\text { Aiello et al. } \\
2012\end{array}$ & $\begin{array}{c}2002- \\
\text { Apr } 2012\end{array}$ & $\begin{array}{l}\text { PubMed, The Cochrane Library, } \\
\text { Scopus, Embase, Ovid of } \\
\text { Medline, PsychINFO, ISI web } \\
\text { of Knowledge }\end{array}$ & $44^{*}$ & $\begin{array}{l}1458 \text { relatives } \\
1314 \text { patients } \\
847 \text { prodromal } \\
\text { subjects } \\
1946 \text { controls }\end{array}$ & not reported & $\begin{array}{c}\text { stress response (cortisol level, } \\
\text { ACTH level), pituitary volume, } \\
\text { hippocampal volume }\end{array}$ \\
\hline $\begin{array}{l}\text { Berger et al. } \\
2016\end{array}$ & $\begin{array}{l}\text { up to July } \\
2015\end{array}$ & $\begin{array}{l}\text { MEDLINE, Scopus, PsycINFO, } \\
\text { Web of Science }\end{array}$ & 11 & $\begin{array}{l}394 \text { cases } \\
398 \text { controls }\end{array}$ & 13-41 years & cortisol awakening response \\
\hline $\begin{array}{l}\text { Borges et al. } \\
2013\end{array}$ & $\begin{array}{l}1985- \\
\text { Oct } 2012\end{array}$ & $\begin{array}{l}\text { PubMed, PsychINFO, Ovid of } \\
\text { Medline, The Cochrane Library }\end{array}$ & $27^{* *}$ & $\begin{array}{l}889 \text { cases } \\
907 \text { controls }\end{array}$ & not reported & cortisol level, pituitary volume \\
\hline $\begin{array}{l}\text { Chaumette } \\
\text { et al. } 2015\end{array}$ & $\begin{array}{l}\text { up to June } \\
2015\end{array}$ & $\begin{array}{l}\text { Medline, Web of Knowledge } \\
\text { (including Web of Science), } \\
\text { EBSCO (including Academic } \\
\text { Search Premier, PASCAL, } \\
\text { PsycARTICLES, Psychology, } \\
\text { Behavioral Sciences Collection), } \\
\text { Clinical Trials database }\end{array}$ & $13^{* * *}$ & $\begin{array}{l}818 \text { cases } \\
631 \text { controls }\end{array}$ & $\begin{array}{l}\text { 15-30 years } \\
\text { (ICAAR } \\
\text { cohort) }\end{array}$ & cortisol level \\
\hline $\begin{array}{l}\text { Ciufolini et } \\
\text { al. } 2014\end{array}$ & $\begin{array}{c}1993- \\
\text { Aug } 2013\end{array}$ & $\begin{array}{l}\text { PubMed, } \\
\text { PsychINFO }\end{array}$ & 3 & $\begin{array}{l}59 \text { cases } \\
65 \text { controls }\end{array}$ & $\begin{array}{l}\text { 19-39 years } \\
\text { (mean 26.3) }\end{array}$ & cortisol level \\
\hline $\begin{array}{l}\text { Fond et al. } \\
2015\end{array}$ & $\begin{array}{l}\text { up to Sep } \\
2014\end{array}$ & $\begin{array}{l}\text { The Cochrane Central Register } \\
\text { of Controlled Trials } \\
\text { (CENTRAL), Medline, Medline } \\
\text { Unindexed, EMBASE, } \\
\text { PsycINFO, Google Scholar }\end{array}$ & $\begin{array}{c}\text { not } \\
\text { clear }\end{array}$ & not clear & not reported & $\begin{array}{c}\text { hormonal biomarkers, peripheral } \\
\text { monoamines and metabolites blood } \\
\text { or urine levels, biomarkers of } \\
\text { immune inflammation and } \\
\text { oxidative stress, candidate genes } \\
\text { polymorphisms }\end{array}$ \\
\hline $\begin{array}{l}\text { Girshkin et } \\
\text { al. } 2014\end{array}$ & $\begin{array}{l}\text { up to June } \\
2014\end{array}$ & $\begin{array}{l}\text { MEDLINE, Embase, BIOSIS } \\
\text { Previews }\end{array}$ & 44 & $\begin{array}{l}1520 \text { cases } \\
1093 \text { controls }\end{array}$ & $\begin{array}{l}\text { 20-52 years } \\
\text { (mean 28) }\end{array}$ & cortisol level \\
\hline $\begin{array}{l}\text { Lange et al. } \\
2016\end{array}$ & $\begin{array}{l}\text { Jan } 1993 \text { - } \\
\text { Aug } 2015 \\
\end{array}$ & $\begin{array}{c}\text { PubMed, } \\
\text { Web of Knowledge }\end{array}$ & 11 & $\begin{array}{l}420 \text { patients and } \\
337 \text { controls }\end{array}$ & 22-41 years & $\begin{array}{l}\text { subjective responses to psycho- } \\
\text { social stress; HPA axis response }\end{array}$ \\
\hline
\end{tabular}

* stress response: 11 studies with 788 participants (228/147/180/233); pituitary volume: 5 studies with 617 participants (182/107/130/198); hippocampal volume: 28 studies with 4160 participants (1048/1060/537/1515)

** cortisol level: 16 studies with 849 participants (473/376); pituitary volume: 11 studies with 947 participants (416/531)

*** UHR (ultra-high risk individuals): 7 studies identified through database search + data from ICAAR cohort (603/457);

FEP: 5 studies identified through database search + data from ICAAR cohort (215/226);

ICAAR cohort: 93 ultra-high risk individuals/52 help-seekers controls/24 individuals with first episode of psychosis

Table 4. AMSTAR score on methodological quality of the included systematic reviews

\begin{tabular}{lcccccccccccc}
\hline \multicolumn{1}{c}{ Study, year } & 1 & 2 & 3 & 4 & 5 & 6 & 7 & 8 & 9 & 10 & 11 & Total \\
score
\end{tabular}

Girshkin et al. conducted a meta-analysis that showed a slight increase in morning cortisol levels in schizophrenia when compared to healthy controls, but with significant heterogeneity among studies. Subgroup analyses revealed bigger effect sizes in schizophrenia when compared to FEP, but neither age nor sex were found to be significant confounders. However, bigger increase in morning cortisol level was observed in those sampled before $8 \mathrm{am}$, and medication status was also found to be significantly associated with morning cortisol levels in people with schizophrenia (Girshkin et al. 2014).

Lange et al. analyzed emotional and endocrinological response to experimentally induced psychosocial stress in patients with schizophrenia spectrum disorder (SSD). They reported that first-onset medication naïve SSD patients may show differences in subjective responses to stress measures and cortisol release, 
unlike chronically ill SSD patients, which could be a correlate of pathophysiological dysfunction of the HPA axis prior or at the onset of SSD (Lange et al. 2016).

\section{Quality assessment of included systematic reviews}

AMSTAR score on the methodological quality of each included systematic reviews is shown in Table 4. Overall, the methodological quality of included systematic reviews was inadequate, with 4 reviews of low quality, 3 reviews of medium quality and 1 review of high quality. Only one of the reviews reported having a priori defined protocol, which was registered in PROSPERO (Lange et al. 2016). The majority of the reviews did not report a list of both included and excluded studies or analyze quality of included studies (Table 4).

\section{Conflict of interest in included systematic reviews}

None of the 8 systematic reviews was funded by forprofit industry; all of them were funded by various nonprofit governmental and non-governmental organizations. Authors of 6 systematic reviews reported having no conflict of interest (Aiello et al. 2012, Berger et al. 2016, Borges et al. 2013, Chaumette et al. 2015, Girshkin et al. 2014, Lange et al. 2016). Authors of two systematic reviews reported having different ties with pharmaceutical industry as potential conflict of interest (Ciufolini et al. 2014, Fond et al. 2015).

\section{DISCUSSION}

The current overview included 8 systematic reviews about the role of stress in the onset of schizophrenia published between 2012 and 2016, of overall inadequate methodological quality.

The main findings of the reviews point out a possible alteration of the stress response, in a subgroup of persons with psychosis proneness. This is observable even before the onset of psychosis in persons at risk suggested by: (i) increased ACTH blood levels in response to stress and increased pituitary volume in relatives of patients with schizophrenia (Aiello et al. 2012), and (ii) a significantly higher salivary basal cortisol levels in patients with ultra-high risk for psychosis compared to controls (Chaumette et al. 2015). Compared to controls, in persons in whom transition to psychosis occurs, increased hippocampal volume (Aiello et al. 2012), higher plasma cortisol levels (Borges et al. 2013) larger pituitary volume (Borges et al. 2013), as well as a basal hyperactivity of the HPA axis (in males only) (Fond et al. 2015) was found. However, in the majority of reviews, conflicting findings were reported as well (Borges et al. 2013, Ciufolini et al. 2014, Girshkin et al. 2014), or authors reported no differences between FEP and controls (Borges et al. 2013). One review found that patients along the psychosis-continuum have a blunted CAR compared to healthy controls, and further subgroup analyzis revealed that this difference is only present in patients with FEP and schizophrenia but not in individuals at high risk for psychosis (Berger et al. 2016). Together with meta-analysis of cortisol levels in patients with schizophrenia that showed elevated morning cortisol compared to controls (Girshkin et al. 2014) and altered HPA-axis response to psychosocial stress that was characterized by lower anticipation and peak cortisol levels (Ciufolini et al. 2014), this represents strong evidence for dysregulated HPA-axis activity in patients with schizophrenia, characterized by a flat diurnal cortisol curve with overall high cortisol levels, and alterations in HPA-axis reactivity to laboratory-induced psychosocial stress. Another review showed that showed that first-episode, medication naive patients with SSD experience e more anxiety and less control during the task than healthy controls and seem to be more disposed to a subjective responses to stress reaction compared to chronically ill patients (Lange et al. 2016).

Some of the observed inconsistencies may be explained with other factors, primarily relating to the methodology of the studies included in the reviews. These include the lack of standardisation of biological assessment methods of stress response (e.g. blood cortisol, salivary cortisol, hippocampal volume, etc.), different or no psychological assessments of stress response, the lack of assessment of treatment methods (Vives et al. 2015), as well as the lack of standardisation of outcomes (e.g. several psychiatric rating scales, different cut-offs and follow-up periods).

Other factors may include the effects of illnessrelated factors such as the duration and severity of the symptoms, or the influence of medication on stress response. This may explain a significant heterogeneity of the studies included in some of the reviews. In particular, longer duration of psychosis was associated with a reduction in pituitary volume (Borges et al. 2013), the severity of illness was found to be correlated with the hyperactivity of HPA axis (Fond et al. 2015) and higher basal cortisol levels were found in patients with schizophrenia compared to patients with FEP or controls (Fond et al. 2015). Somatic comorbidities (e.g. chronic illnesses such as diabetes) which may influence stress response as well, were not assessed in the reviews (Wosu et al. 2013).

Lastly, antipsychotic medication, other psychoactive substances, as well as other forms of treatment that may mediate stress response were not systematically assessed in the reviews. For example, prolactin-enhanced antipsychotics were associated with larger pituitary volume (Borges et al. 2013). Anti-inflammatory drugs, which are available over the counter and easily accessible to controls and patients may possibly influence stress response as well (Di Luigi et al. 2007). The use of cannabis, which is quite common among persons with FEP (Marconi et al. 2016), may affect the 
levels of salivary cortisol (King et al. 2011, Monteleone et al. 2014). Lastly, treatment with psychotherapies and meditation-like techniques that may alter stress response were not assessed in those studies as well (Jensen et al. 2015, Rosenkranz et al. 2016).

\section{Limitations}

The following limitations of this overview were noted: (i) Methodological quality of included systematic reviews was not high. Future systematic reviews should follow relevant checklist for methodological quality to improve quality of evidence from secondary research. (ii) In general, no information on participants that may be relevant for overall stress response were included in the review. These include somatic comorbidities of the patients, the use of anti-inflammatory medication, the use of psychiatric medication, the use of marijuana, the use of alternative or additional treatment, like mediation, yoga, psychotherapy. (iii) Clinically relevant outcomes were not analyzed. First, reviews failed to analyze the association of alterations of biological stress biomarkers (i.e. cortisol) with clinically meaningful findings such as overall vulnerability to stress using scales of stressful events, or scales of daily hassles, stress response to provoking stimuli. Secondly, reviews did not analyze clinical outcomes of longitudinal studies that assess stress response in different state of the FEP (at risk, acute psychosis, remission of symptoms, functional remission) and different state of treatment (i.e., psychotherapy, medications such as antipsychotics).

\section{Clinical implications}

The aim of this review was to ascertain whether alterations of stress response found in persons at risk for schizophrenia and FEP may serve as a marker that may predict psychotic episodes and serve as a biological marker of treatment response, and serve as a treatment tool in clinical practice.

However, given the heterogeneity of current results, there is no solid evidence for uniform alterations of stress response found in persons with FEP that may serve as a marker of vulnerability to stress and possibly proneness to psychotic state in response to daily hassles.

\section{Implications for future research}

Given the initial aims of the review, as well as the current limitations of this overview, future systematic reviews should (i) include systematic reviews that follow relevant checklist for methodological quality to improve quality of evidence from secondary research. (ii) Include studies that analyzed the influence of stress on psychosis with more than one biological marker of stress response (i.e. awakening plasma cortisol, awakening salivary cortisol, cortisol in response to stress stimuli) which could improve reliability of the studies. (iii) All systematic reviews should take into account the effects of potential factors in the studies that may influence stress response (e.g. marijuana use, drugs, chronic illnesses, etc.). (iv) Include studies that analyze clinical outcomes such as overall vulnerability to stress using scales of stressful events, or scales of daily hassles, stress response to provoking stimuli over a longitudinal period encompassing a different state of the FEP (at risk, acute psychosis, remission of symptoms, functional remission) and different state of treatment (i.e., psychotherapy, medications such as antipsychotics).

\section{Acknowledgements:}

This work was funded by the grant of the Croatian Science Foundation (HRZZ) No. UIP-2014-09-1245 "Biomarkers in schizophrenia - integration of complementary methods in longitudinal follow up of first episode psychosis patients".

Conflict of interest: None to declare.

\section{Contribution of individual authors:}

Study conception and design: Linda Rossini Gajsak \& Livia Puljak;

Acquisition of data, or analysis and interpretation of data: Linda Rossini Gajsak, Andrea Gelemanovic, Martina Rojnic Kuzman \& Livia Puljak;

Drafting the article or revising it critically for important intellectual content: Linda Rossini Gajsak, Andrea Gelemanovic, Martina Rojnic Kuzman \& Livia Puljak;

Final approval of the version to be published: Linda Rossini Gajsak, Andrea Gelemanovic, Martina Rojnic Kuzman \& Livia Puljak.

\section{References}

1. Aiello G, Horowitz M, Hepgul N, Pariante CM, Mondelli V: Stress abnormalities in individuals at risk for psychosis: A review of studies in subjects with familial risk or with "at risk" mental state. Psychoneuroendocrinology 2012; 37:1600-1613.

2. Bale TL, Baram TZ, Brown AS, Goldstein JM, Insel TR, McCarthy MM, Nemeroff CB, Reyes TM, Simerly RB, Susser ES, Nestler EJ: Early life programming and neurodevelopmental disorders. Biological psychiatry 2010; 68:314-319.

3. Beards S, Gayer-Anderson C, Borges S, Dewey ME, Fisher HL, Morgan C: Life events and psychosis: a review and meta-analysis. Schizophrenia bulletin 2013; 39:740-747.

4. Berger M, Kraeuter AK, Romanik D, Malouf P, Amminger GP, Sarnyai Z: Cortisol awakening response in patients with psychosis: Systematic review and meta-analysis. [Review]. Neuroscience \& Biobehavioral Reviews 2016; 68:157-166.

5. Borges S, Gayer-Anderson C, Mondelli V: A systematic review of the activity of the hypothalamic-pituitary-adrenal axis in first episode psychosis. Psychoneuroendocrinology 2013; 38:603-611. 
6. Chaumette B, Kebir O, Mam-Lam-Fook C, Morvan Y, Bourgin J, Godsil BP, Plaze M, Gaillard R, Jay TM, Krebs MO: Salivary cortisol in early psychosis: New findings and meta-analysis. Psychoneuroendocrinology 2015; 63:262-270.

7. Ciufolini S, Dazzan P, Kempton MJ, Pariante C, Mondelli $V$ : HPA axis response to social stress is attenuated in schizophrenia but normal in depression: evidence from a meta-analysis of existing studies. Neuroscience \& Biobehavioral Reviews 2014; 47:359-368.

8. Cullen AE, Zunszain PA, Dickson H, Roberts RE, Fisher $H L$, Pariante CM, Laurens KR: Cortisol awakening response and diurnal cortisol among children at elevated risk for schizophrenia: relationship to psychosocial stress and cognition. Psychoneuroendocrinology 2014; 46:1-13.

9. Di Luigi L, Rossi C, Sgro P, Fierro V, Romanelli F, Baldari C, Guidetti L: Do non-steroidal anti-inflammatory drugs influence the steroid hormone milieu in male athletes? Int J Sports Med 2007; 28:809-814.

10. Emsley R, Chiliza B, Asmal R, Harvey BH: The nature of relapse in schizophrenia. BMC Psychiatry 2013; 13:50.

11. Fond G, d'Albis M-A, Jamain S, Tamouza R, Arango C, Fleischhacker $W W$, Glenthoj B, Leweke $M$, Lewis $S$, McGuire P, Meyer-Lindenberg A, Sommer IE, Winter-van Rossum I, Kapur S, Kahn RS, Rujescu D, Leboyer M: The promise of biological markers for treatment response in first-episode psychosis: A systematic review. [References]. Schizophrenia Bulletin 2015; 41:559-573.

12. Gardiner EJ, Cairns MJ, Liu B, Beveridge NJ, Carr V, Kelly B, Scott RJ, Tooney PA: Gene expression analysis reveals schizophrenia-associated dysregulation of immune pathways in peripheral blood mononuclear cells. Journal of psychiatric research 2013; 47:425-437.

13. Girshkin L, Matheson SL, Shepherd AM, Green MJ: Morning cortisol levels in schizophrenia and bipolar disorder: a meta-analysis. Psychoneuroendocrinology 2014; 49:187-206.

14. Holtzman CW, Trotman HD, Goulding SM, Ryan AT, Macdonald AN, Shapiro DI, Brasfield JL, Walker EF: Stress and neurodevelopmental processes in the emergence of psychosis. Neuroscience 2013; 249:172-191.

15. Jaaskelainen E, Juola P, Hirvonen N, McGrath JJ, Saha $S$, Isohanni M, Veijola J, Miettunen J: A systematic review and meta-analysis of recovery in schizophrenia. Schizophrenia bulletin 2013; 39:1296-1306.

16. Jensen CG, Lansner J, Petersen A, Vangkilde SA, Ringkobing SP, Frokjaer VG, Adamsen D, Knudsen GM, Denninger JW, Hasselbalch SG: Open and Calm - A randomized controlled trial evaluating a public stress reduction program in Denmark. Bmc Public Health 2015; 15.

17. Kahn RS, Fleischhacker WW, Boter H, Davidson M, Vergouwe Y, Keet IP, Gheorghe MD, Rybakowski JK, Galderisi S, Libiger J, Hummer M, Dollfus S, Lopez-Ibor $J J$, Hranov LG, Gaebel W, Peuskens J, Lindefors N, Riecher-Rossler A, Grobbee DE: Effectiveness of antipsychotic drugs in first-episode schizophrenia and schizophreniform disorder: an open randomised clinical trial. Lancet 2008; 371:1085-1097.

18. King GR, Ernst T, Deng WR, Stenger A, Gonzales RMK, Nakama H, Chang LD: Altered Brain Activation During Visuomotor Integration in Chronic Active Cannabis Users: Relationship to Cortisol Levels. J Neurosci 2011; 31:17923-17931.
19. Lange C, Deutschenbaur L, Borgwardt S, Lang UE, Walter M, Huber CG: Experimentally induced psychosocial stress in schizophrenia spectrum disorders: A systematic review. [Review]. Schizophrenia Research 2016; 09, 09.

20. Marconi A, Di Forti M, Lewis CM, Murray RM, Vassos E: Meta-analysis of the Association Between the Level of Cannabis Use and Risk of Psychosis. Schizophrenia bulletin 2016; 42:1262-1269.

21. Miller BJ, Buckley P, Seabolt W, Mellor A, Kirkpatrick B: Meta-analysis of cytokine alterations in schizophrenia: clinical status and antipsychotic effects. Biological psychiatry 2011; 70:663-671.

22. Mizrahi R, Addington J, Rusjan PM, Suridjan I, $\mathrm{Ng}$ A, Boileau I, Pruessner JC, Remington G, Houle S, Wilson AA: Increased stress-induced dopamine release in psychosis. Biological psychiatry 2012; 71:561-567.

23. Monteleone P, Di Filippo C, Fabrazzo M, Milano W, Martiadis V, Corrivetti $G$, Monteleone AM, Maj M: Flattened cortisol awakening response in chronic patients with schizophrenia onset after cannabis exposure. Psychiatry research 2014; 215:263-267.

24. O'Connor JA, Wiffen B, Diforti M, Ferraro L, Joseph C, Kolliakou A, Bonaccorso S, Murray RM, David AS: Neuropsychological, clinical and cognitive insight predictors of outcome in a first episode psychosis study. Schizophrenia research 2013; 149:70-76.

25. Pruessner M, Bechard-Evans L, Boekestyn L, Iyer SN, Pruessner JC, Malla AK: Attenuated cortisol response to acute psychosocial stress in individuals at ultra-high risk for psychosis. Schizophrenia research 2013; 146:79-86.

26. Rosenkranz MA, Lutz A, Perlman DM, Bachhuber DRW, Schuyler BS, MacCoon DG, Davidson RJ: Reduced stress and inflammatory responsiveness in experienced meditators compared to a matched healthy control group. Psychoneuroendocrinology 2016; 68:117-125.

27. Shea BJ, Grimshaw JM, Wells GA, Boers M, Andersson N, Hamel C, Porter AC, Tugwell P, Moher D \& Bouter LM: Development of AMSTAR: a measurement tool to assess the methodological quality of systematic reviews. BMC Medical Research Methodology, 2007.

28. van Os J, Kapur S: Schizophrenia. Lancet 2009; 374:635645.

29. Van Winkel R, Esquivel G, Kenis $G$, Wichers M, Collip D, Peerbooms O, Rutten B, Myin-Germeys I, Van Os J: REVIEW: Genome-wide findings in schizophrenia and the role of gene-environment interplay. CNS Neurosci Ther 2010; 16:e185-92.

30. Vives AH, De Angel V, Papadopoulos A, Strawbridge R, Wise T, Young AH, Arnone D, Cleare AJ: The relationship between cortisol, stress and psychiatric illness: New insights using hair analysis. Journal of psychiatric research 2015; 70:38-49.

31. Walker FR, Pfingst K, Carnevali L, Sgoifo A, Nalivaiko E: In the search for integrative biomarker of resilience to psychological stress. Neurosci Biobehav Rev 2016; pii:S0149-7634(15)30360-2.

32. Wittchen HU, Jacobi F, Rehm J, Gustavsson A, Svensson $M$, Jonsson B, Olesen $J$, Allgulander C, Alonso $J$, Faravelli C, Fratiglioni L, Jennum P, Lieb R, Maercker $A$, van Os $J$, Preisig $M$, Salvador-Carulla L, Simon $R$, Steinhausen HC: The size and burden of mental disorders and other disorders of the brain in Europe 
2010. European Neuropsychopharmacology 2011; 21:655-679.

33. Wosu AC, Valdimarsdottir $U$, Shields AE, Williams $D R$, Williams MA: Correlates of cortisol in human hair: implications for epidemiologic studies on health effects of chronic stress. Ann Epidemiol 2013; 23:797-811.

34. Wunderink L, Nieboer RM, Wiersma D, Sytema S, Nienhuis FJ: Recovery in remitted first-episode psychosis at 7 years of follow-up of an early dose reduction/ discontinuation or maintenance treatment strategy: longterm follow-up of a 2-year randomized clinical trial. JAMA Psychiatry 2013; 70:913-920.

35. Zannas AS, West AE: Epigenetics and the regulation of stress vulnerability and resilience. Neuroscience 2014; 264:157-170.

\section{Correspondence:}

Linda Rossini Gajsak, MD

Department of Biological Psychiatry, Neuropsychiatric Hospital Dr. Ivan Barbot Jelengradska 1, 44314 Popovaca, Croatia

E-mail:lrgajsak@gmail.com 